\title{
Doença versus saúde: como os idosos se percebem diante desses conceitos
}

\author{
Sandra Carolina Farias de Oliveira*; Maria Isabel Patrício de Carvalho Pedrosa**; \\ Maria de Fátima Souza Santos*****
}

\section{Resumo}

Este artigo tem como objetivo verificar se os idosos se percebem como doentes e se essa condição afeta sua rotina diária. Para tanto, foi realizada uma pesquisa com cem idosos de 60 a 97 anos numa cidade do Sertão Pernambucano, com estado mental preservado, ou seja, todos com estado de lucidez. Em seus domicílios, os idosos responderam a entrevistas guiadas por um roteiro semiestruturado com questões sobre seu cotidiano e contextualização de vida. Numa segunda parte, foram-Ihes apresentadas palavras ou frases que deveriam ser por eles associadas às diversas faixas etárias - criança, jovem, adulto e idoso. Os resultados apontam para uma ideia compartilhada pelos idosos de que estão numa faixa etária em que mais adoecem e reconhecem alguma morbidade que modifica e influencia na sua rotina diária. Isso Ihes causa tristeza, principalmente pelo sentimento de inutilidade acarretado pelas enfermidades. Esses resultados podem subsidiar ações que beneficiem os idosos, propiciando-lhes uma maior integração social.

Palavras-chave: Saúde. Doença. Idoso. Rural.

\section{Introdução}

De acordo com Camarano (2002), os estudos sobre o envelhecimento humano são relativamente recentes. No meio acadêmico brasileiro tiveram início na década de 1960 e o seu aumento acompanha, de certo modo, o envelhecimento populacional, que vem se alastrando em escala mundial, atingindo diversos países, entre os quais o Brasil. Tal fato parece ter despertado o interesse por essa fase do desenvolvimento, o que pode ser verificado em instâncias diversas, seja pela crescente produção científica sobre essa população, seja pelo destaque que assuntos relativos aos idosos têm conseguido na mídia, pelas estratégias de marketing especialmente voltadas para esse segmento populacional, seja, ainda, pela preocupação em desenvolver uma política nacional para as pessoas idosas. (BRASIL, 1996).

Diferentes autores (VERAS, 1994, 2003; NERI, 1991; KALACHE, 2007)

* Psicóloga. Mestra em Psicologia pela Universidade Federal de Pernambuco. Endereço para correspondência: Sandra Carolina Farias de Oliveira, Rua Santa Cruz do Capibaribe, 93, CEP 50870-620, Bairro Areias, Recife - PE. E-mail: sandrapsifarias@yahoo.com.br.

* Psicóloga e Doutora em Psicologia pela Universidade de São Paulo. Professora Associada do Departamento de Psicologia da Universidade Federal de Pernambuco. Pesquisadora bolsista do CNPq.

*** Psicóloga e Doutora em Psicologia pela Universidade Federal de Pernambuco. Professora Associada do Departamento de Psicologia da Universidade Federal de Pernambuco. Pesquisadora bolsista do CNPq.

$\zeta$ Recebido em junho de 2008 - Avaliado em março de 2009.

$\longrightarrow$ doi:10.5335/rbceh.2009.017 
retratam essa nova realidade: o Brasil é hoje um país que vem envelhecendo rapidamente. (KALACHE; VERAS; RAMOS, 1987).

O envelhecimento humano é, antes de tudo, um processo biológico, logo, natural e universal. O homem, como os outros animais, segue um contínuo processo de desenvolvimento, que o leva necessariamente à velhice e à morte. No entanto, diferencia-se dos outros animais por uma série de características, entre as quais se pode destacar o fato de que ele é, ao mesmo tempo, produtor e produto de uma sociedade, de uma cultura, e tem a consciência de si enquanto ser finito, isto é, tem consciência de seu processo de envelhecimento e de sua própria morte. Entretanto, a velhice é também uma convenção sociocultural. Aidade em que alguém é reconhecido e se reconhece como velho e os sentidos atribuídos à velhice variam ao longo do tempo e nas diferentes culturas.

No que se refere à "idade da velhice”, a Organização das Nações Unidas define os idosos nos países desenvolvidos a partir de 65 anos e, nos países em desenvolvimento, a partir dos sessenta anos. No Brasil a lei no 10.741, de 1ํ de outubro de 2003 , define essa parcela da população como "pessoas com idade igual ou superior a 60 (sessenta) anos". Porém, muitas sociedades caracterizamna segundo outras referências, por exemplo, como a capacidade de produção e a aparência física.

Mesmo no Brasil, a velhice na zona urbana é, em geral, considerada como ausência de saúde, ao passo que na zona rural o sujeito se considera velho a partir do momento em que não consegue mais trabalhar. (SANTOS; BELO, 2000).

Albuquerque (2005), em sua tese de doutorado, chama a atenção de que uma definição do que é ser velho deve considerar a heterogeneidade desse grupo social, a relação entre os aspectos biológicos e culturais e a finalidade do conceito social de idoso.

Diversos estudos demonstram que a velhice é, em geral, associada a inutilidade e ausência de saúde. (SANTOS; BELO, 2000; ALMEIDA; SANTOS, 2002). Ser velho é quase sinônimo de ser doente.

O conceito de saúde, assim como o de velhice, é polêmico entre os estudiosos das diversas áreas. $\mathrm{O}$ que parece quase unanimidade na população em geral é a associação entre saúde e doença, a qual existe desde os egípcios. (CANGUILHEM, 1995). Na definição de saúde e doença, outra ideia subjacente e controversa é a separação entre corpo e mente.

Atualmente, o conceito de saúde predominante é o proposto pela Organização Mundial de Saúde, que data de 1987. Para a OMS a saúde é um estado de perfeito bem-estar físico, mental e social, não apenas ausência de doença.

O conceito apresentado é considerado utópico já que as pessoas, concretamente, nunca irão atingir um total bemestar em todos os aspectos de sua vida. Ao tomar o bem-estar como parâmetro, deve-se, portanto, levar em contar a percepção de cada um sobre o seu próprio bem-estar. A subjetividade de cada um será uma importante variável nessa definição. Critica-se, ainda, o fato de definir 
separadamente bem-estar físico, mental e social, uma vez que tal definição traz em seu bojo a separação entre as diversas instância da vida do ser humano. Espera-se de um conceito atulizado a integração, não a dissociação desses aspectos. (SEGRE; FERRAZ, 1997).

Como forma de minimizar esses questionamentos, alguns autores falam de qualidade de vida. Ter saúde é ter uma vida considerada pelo próprio sujeito como uma vida com qualidade; porém, mais uma vez a variável subjetividade limita essa definição.

O assunto é ainda mais complexo quando se fala da saúde na terceira idade. Em sua maioria, os idosos apresentam alguma disfunção crônica; por isso, são considerados doentes de acordo com o conceito da OMS. Porém, podemos perceber que muitos deles lidam bem com suas disfunções, mantendoas sob controle, razão por que não se consideram doentes. Sobre isso Ramos (2002) refere-se ao novo paradigma em saúde, que é o conceito de "capacidade funcional". Este conceito se relaciona com a capacidade do indivíduo de gerir e realizar suas atividades com autonomia. Assim, "o bem-estar na velhice, ou saúde num sentido amplo, seria o resultado do equilíbrio entre as várias dimensões da capacidade funcional do idoso, sem necessariamente significar ausência de problemas em todas as dimensões". (RAMOS, 2002).

\section{Método}

Caracterização da cidade escolhida para a pesquisa

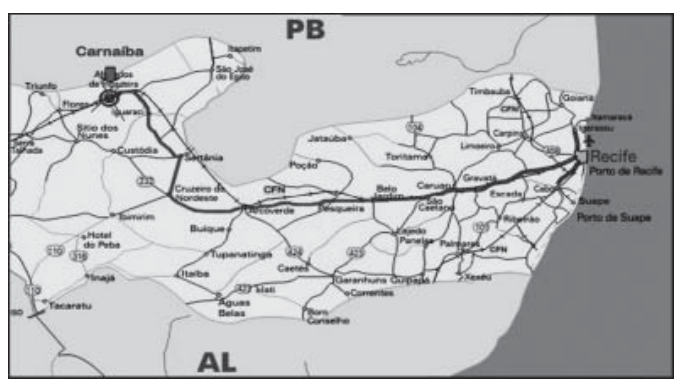

Figura 1 -Mapa de Pernambuco indicando a cidade onde foi realizada a pesquisa.

A cidade escolhida para a realização da pesquisa, Carnaíba (as informações foram adquiridas no site oficial da cidade: www.carnaiba.pe.gov.br), localiza-se na mesorregião do Sertão de Pernambuco e na microrregião do Sertão do Alto Pajeú, distante $420 \mathrm{~km}$ da capital Recife. Tem como principais características o clima tropical semiárido, com temperaturas acima de $27^{\circ} \mathrm{C}$, a caatinga como vegetação predominante, a economia baseada na agricultura e comércio e uma população bastante religiosa. Carnaíba sobrevive ao intenso calor e seca.

De acordo com dados do Instituto Brasileiro de Geografia e Estatística, em 2000 Carnaíba contava com 17.696 habitantes, dos quais 6.560 viviam na zona urbana e 11.136, na zona rural. Quanto à população idosa, os dados da Secretaria do Idoso do Estado de Pernambuco registram um total de 1.715 indivíduos que apresentam idade superior a sessenta anos. Portanto, pode-se verificar que aproximadamente $10 \%$ da 
população encontram-se na faixa etária considerada como velhice. Justifica-se e reforça-se a importância de se ter realizado a pesquisa nessa cidade por se tratar de uma cidade envelhecida.

\section{Participantes}

Foram selecionados cem indivíduos com idade igual ou superior aos sessenta anos cadastrados nas unidades de PSFs da cidade de Carnaíba. Ao todo foram 77 mulheres e 23 homens, com idades que variaram entre 60 e 97 anos. É importante salientar que todos os indivíduos tinham discernimento para escolher se desejavam ou não participar da pesquisa, considerando os aspectos mostrados a eles no "termo de consentimento livre e esclarecido"; apresentavam as funções cognitivas conservadas (não demonstravam possuir nenhum quadro demencial, ou patologia que comprometesse sua lucidez) e tinham suas habilidades físicas preservadas, ou seja, não apresentavam nenhuma enfermidade que atrapalhasse seu desempenho na realização das atividades que estavam sendo propostas (surdez, afasias ou ausência de linguagem oral). A coleta foi realizada no domicílio dos idosos.

\section{Materiais}

Para a coleta dos dados foi utilizado um roteiro de entrevista semiestruturado. Utilizou-se ainda um "mp3 Player" para registrar a entrevista, assim como lápis e papel para alguma anotação relevante. O roteiro de entrevista compunhase de dois conjuntos de questões: uma caracterização do contexto de vida, com perguntas direcionadas ao modo como as pessoas estão vivendo, e uma segunda parte com associações, nas quais os idosos deveriam associar as frases/palavras apresentadas às diferentes faixas etárias: criança, jovem, adulto ou idoso. Desse modo foi possível analisar se os idosos estão associando sua condição de vida atual ao ser doente e triste.

\section{Procedimentos}

Em primeiro lugar, é importante salientar que este projeto de pesquisa seguiu as normas estabelecidas pela Comissão Nacional de Saúde na resolução de nº ${ }^{-196}$, de 10 de outubro de 1996, com registro de $\mathrm{n}^{0} 077 / 07$, sendo liberado para a coleta no dia 26 de junho de 2007. Após, iniciou-se um contato com a Prefeitura da cidade com o intuito de verificar qual seria a melhor forma de encontrar esses participantes. A solução encontrada foi realizar a pesquisa junto às equipes de PSFs. A vantagem de se realizar a pesquisa junto aos PSFs foi a utilização da listagem de sujeitos idosos, agilizando a localização dos participantes (da zona rural e urbana), além de que um idoso abordado em sua casa muitas vezes já indicava um colega ou parente, até se completar o número proposto pela pesquisa. Coletados os dados, as entrevistas foram analisadas e quantificadas pela pesquisadora, obtendo-se um olhar quantitativo e qualitativo dos resultados.

\section{Resultados e discussão}

É importante informar que dos cem idosos entrevistados todos tomavam 
medicação em decorrência de alguma complicação de saúde. Contudo, é interessante notar que nem por isso eles se consideravam doentes.

Faço (tratamento de saúde), mas tomo remédio e tá tudo controlado [...] remédio eu só tomo de 2, 3 pra colesterol, coração e pra fazer cocô.

Nós não tem doença, a única doença que tenho é a coluna.

Não tenho nada, só um problema nos ossos.

Vale a pena ressaltar que, por mais que se tente dissociar a ideia de corpo e mente, os indivíduos não fazem essa dissociação. Principalmente quando se trata do idoso, eles tendem a referir muito a relação existente entre soma e psique, ou seja, a psicossomática, visto que os "aperreios" que têm afetam diretamente a pressão arterial, o coração, a tontura.

Ah, minha filha, eu tenho um problema nas pernas que ando apulso, tenho problema de coluna, tenho pressão alta... Qualquer aperreio já fica doente. Eu não tendo aperreio, tudo corre bem.

Quando minha mulher morreu, minha pressão subiu, alterou um pouco.

Faço, eu assim, por causa de muita preocupação, eu apresentei labirinto. Aí eu tomo remédio uma semana, duas, aí paro. Passo um monte de tempo sem preocupação, dormindo bem.

Não faço nada, mas quando minha irmã morreu agora ela ficou bem alta (pressão), faz quatro meses que ela morreu.

No que diz respeito à questão de quem fica mais doente e triste, os escores obtidos foram: 67 dos entrevistados relataram que os idosos são os que mais adoecem e ficam tristes. A resposta "to- dos" foi citada 13 vezes; "adulto", 8 vezes; "criança", 9; "jovem", 3. Esses resultados remetem à sua história de vida atual, já que grande parte das doenças que acometem os idosos são crônicas e prejudicam o andamento de sua rotina diária. Sendo característica da população o trabalho baseado na agricultura, eles só deixam de trabalhar quando alguma doença os impede. Por essa razão, a doença é razão da tristeza deles, por não terem atividade, sentindo-se inúteis, principalmente no que se refere ao gênero masculino. Por se tratar de uma cultura machista, os homens não realizam atividades domésticas, como lavar louça, roupa, varrer a casa. Por sua vez, as mulheres, além de trabalhar na lavoura, realizam tais atividades; por isso, sempre têm afazeres e se mantêm ocupadas.

As mesmas de antes, faço tudo: comida, lavo roupa, engomo, cuido dessa menina porque a mãe dela trabalha, faço tudo como se tivesse quinze anos. (Feminino)

A luta da casa mesmo. (Feminino)

Hoje não faço mais nada, trabalhar velho desse jeito, com 81 anos. Aí não trabalho, vivo assim da minha aposentadoria. (Masculino)

Comer e dormir, não faço mais nada, sou doente da coluna, da cabeça. (Masculino)

$\mathrm{O}$ sentimento de tristeza relatado durante as entrevistas quando os idosos se referiam à doença apresentada é bastante subjetivo e abre um leque de muitas interpretações sobre as possíveis causas. O que se pode dizer é que a doença que tira o indivíduo das atividades relacionadas ao trabalho - agricultura deixa-o com um grande vazio, representado em suas falas pela ideia de inutilidade como se veem. 
Me criei na roça, faz oito anos que saí porque não pude mais trabalhar por causa da coluna [...]. Não to fazendo nada, só comendo, nem dormindo não to direito porque fico preocupada com a casa.

Eu trabalho em casa, ajeitando a casa por aí [...]. Não é fácil não, porque estou com um problema no braço e faço tratamento duas vezes por semana [...]. Além desse do braço, tenho um problema na próstata, que já fui operado faz três anos e faço exame quase todo ano, sou muito doente.

Eu só faço comer e dormir. A irmã cuida na casa e faz almoço, ela é dez anos mais nova do que eu. Vem uma sobrinha e arruma a casa também [...]. Não, eu tinha muito a pressão alta, mas tomo remédio. E eu comia muito doce, aí o médico falou: "Você tem que parar de comer doce." Eu abusei de doce.

\section{Algumas considerações}

Este estudo teve como principal objetivo desvendar como os idosos se veem diante do conceito de saúde/doença e se isso afeta a forma como realizam suas atividades diárias. Pelas falas expostas percebe-se que o idoso não está satisfeito com a vida que tem hoje, revelando uma qualidade de vida prejudicada. Tanto no conceito da OMS quanto no conceito de gerontólogos, verificou-se a importância de um estudo em que se aprofundem as reais necessidades dessa parcela da população para que se sinta saudável.

Como afirmado anteriormente, a doença é uma constante na vida dos idosos e limita bastante suas atividades, o que os deixa tristes. Contudo, pode-se dizer que a pesquisa realizada conseguiu atender aos seus objetivos ao oferecer dados para a compreensão de como o idoso de uma cidade do Sertão Pernambucano entende sua própria saúde/doença. Vale ressaltar a contradição em seus discursos quando falam de si, pois sua doença é minimizada, e quando falam pela classe dos idosos, percebendo que os idosos estão mais doentes.

Pode-se fazer um paralelo dessa ideia do ser doente com o próprio conceito de velhice, visto que não existe um consenso sobre o que é ser velho, ou melhor, quando se começa a ser velho. Santos (1998) apresenta em um de seus textos o quanto a representação da velhice ameaça os indivíduos, levando-os a fazerem uma construção do que é ser velho sempre se reportando a um outro, como forma de afastar de si características negativas associadas a essa fase da vida, como mostrado a seguir:

O verdadeiro velho é o outro - neste sentido, os sujeitos enfatizam o estágio final da velhice como fase de dependência total. Assim, há sempre um "outro" mais velho que ele. $\mathrm{Pa}$ rece importante salientar, que ao destacar aspectos negativos da velhice que de certo modo ameaçam a identidade do sujeito, alguns mecanismos de defesa são acionados. Assim, há sempre um outro mais velho que concretizaria as características negativas da velhice. (SANTOS, 2000, p. 158).

Com o ser doente acontece o mesmo. Então, ao mesmo tempo em que os entrevistados apontam que os idosos hoje apresentam um maior comprometimento de sua saúde, negam que estejam dentro desse grupo. Com os indivíduos do gênero masculino essa questão fica ainda mais evidente, pois em hipótese alguma eles querem demonstrar a fragilidade em que se encontram. Apesar de não retratar um sentimento de fracasso diante da vida hoje, aparentemente eles 
sofrem mais com as doenças, porque trazem a limitação ou total extinção de suas atividades. Com as mulheres isso não acontece, pois elas permanecem cumprindo as obrigações como donas de casa, mesmo que sejam mínima, em razão das suas limitações físicas.

Uma primordial consideração que a pesquisa traz é a importância de se olhar para a faixa etária dos sessenta anos e mais de forma diferenciada. As doenças e as limitações (físicas, psicológicas e sociais) são inúmeras e o apoio social se faz muito importante para ajudar o idoso a lidar melhor com tais questões.

Disease versus health: how the elderly perceive themselves within these concepts

\section{Abstract}

This article aims to verify whether the elderly perceive themselves as ill and if this condition affects their daily routine. Thus, a research was conducted involving 100 elderly aging 60 to 97 , with preserved mental status, ie, all of them lucid, residents in a city hinterland in Pernambuco state. In their homes, they responded to interviews from a semi-structured scheme, with questions about their daily life and its context. In a second part, they were given words or phrases with which they were supposed to associate them to various age groups - children, youth, adult and elderly. The results point to an idea shared by the elderly that they are at an age most likely to become ill and they also recognize a sort of morbidity that provokes changes and affects their daily routine. This causes them grief, especially due to the feeling of uselessness caused by the disease. These results may lead to actions that would benefit the elderly by providing them with greater social integration.

Key words: Health. Disease. Elderly. Rural.

\section{Referências}

ALBUQUERQUE, S. M. R. L. Envelhecimento ativo: desafio dos serviços de saúde para a melhoria da qualidade de vida dos idosos. Tese (Doutorado em Medicina) - Universidade de São Paulo, São Paulo 2005. Disponível em: <www.teses.usp.br/teses/ disponiveis/5/5160/tde-22092005-125548>. Acesso em: 6 maio 2006.

ALMEIDA, A. M. O.; SANTOS, M. F. S. $\mathrm{O}$ envelhecer: teorias científicas $\mathrm{x}$ teorias populares. Psico, Porto Alegre, v. 33, n. 2, p. 311-326, 2002.

BEZERRA JR, B. Normal e patológico: do vitalismo ao mecanicismo. Rio de Janeiro: Cadernos Cepia, 1998.

BRASIL. Decreto $n^{\circ} 1.948$, de 3 de Julho de 1996. Regulamenta a lei $\mathrm{n}^{-} 8.842$, de 4 de Janeiro de 1994, que dispõe sobre a Política Nacional do Idoso, e dá outras providências. Disponível em: <www.jusbrasil.com.br/ legislacao/109143/decreto-1948-96>. Acesso em: 14 jul. 2009.

Lei $n^{\circ}$ 10.741, de 1 de outubro de 2003. Dispõe sobre o Estatuto do Idoso e dá outras providências. Disponível em: <www. planalto.gov.br/ccivil/LEIS/2003/L10.741. htm>. Acesso em: 15 abr. 2006.

CAMARANO, A. A.; KANSO, S.; MELLO, J. L. E. Como vive o idoso brasileiro? Rio de Janeiro: Ipea, 1999.

CAMARANO, A. A. Envelhecimento da população brasileira: uma contribuição demográfica. Rio de Janeiro: Ipea, 2002.

CANGUILHEM, G. O normal e o patológico. Rio de Janeiro: Forense Universitária, 1995. 
KALACHE, A.; VERAS, R. P.; RAMOS, L. R. O envelhecimento da população mundial: um desafio novo. Saúde Pública, São Paulo, v. 21, n. 3, p. 200-210, jun. 1987. Disponível em: <www.scielo.br/scielo.php?script=sci_ arttext\&pid=S0034-89101987000300005$\& \operatorname{lng}=$ en $\&$ nrm=iso $>$. Acesso em: 6 jun. 2006.

KALACHE, A. Fórum. Envelhecimento populacional e as informações de saúde do PNAD: demandas e desafios contemporâneos. Posfácio. Cadernos Saúde Pública, Rio de Janeiro, v. 23, n. 10, p. 733-740, out. 2007. Disponível em: <www.scielo.br/ scielo.php?script $=$ sci_arttext\&pid $=\mathrm{S} 0102$ $311 X 2007001000024 \& \operatorname{lng}=\mathrm{en} \& n r m=i s o>$. Acesso em: 6 jun. 2006.

NERI, A. L. Envelhecer num país de jovens: significados de velho e velhice segundo brasileiros não idosos. Campinas: Unicamp, 1991.

RAMOS, L. R. Fatores determinantes do envelhecimento saudável em idosos residentes em centro urbano: Projeto Epidoso, São Paulo. Cadernos Saúde Pública, Rio de Janeiro, v. 19, n. 3, p. 793-797, jun. 2003. Disponível em: <www.scielosp.org/scielo. php? script $=$ sci_arttext\&pid $=$ S0102 -311 $\mathrm{X} 2003000300011 \& \operatorname{lng}=\mathrm{en} \& n \mathrm{~nm}=\mathrm{iso}>$. Acesso em: 15 maio 2006.

SANTOS, M. F. S. Representação social e identidade. In: MOREIRA, A. S. P.; OLIVEIRA, C. Estudos interdisciplinares de representação social. 2. ed. Goiânia: AB, 2000. p. 151-159.

SANTOS, M. F. S.; BELO, I. Diferentes formas de velhice. Psico, Porto Alegre, v. 31, n. 2, p. 31-48, 2000.

SEGRE, M.; FERRAZ, F. C. O conceito de saúde. Saúde Pública, São Paulo, v. 31, n. 5, p. 538-542, out. 1997. Disponível em: <www.scielosp.org/scielo.php?script=sci_ arttext\&pid=S0034-89101997000600016$\& \operatorname{lng}=$ en\&nrm=iso $>$. Acesso em: 21 jul. 2006.
VERAS, R. País jovem com cabelos brancos: a saúde do idoso no Brasil. Rio de Janeiro: Relume Dumará, 1994.

Em busca de uma assistência adequada à saúde do idoso: revisão da literatura e aplicação de um instrumento de detecção precoce e de previsibilidade de agravos. Cadernos Saúde Pública, Rio de Janeiro, v. 19, n. 3, p. 705-715, jun. 2003. Disponível em: <www.scielo.br/scielo. php?script $=$ sci_arttext\&pid $=$ S0102-311$\mathrm{X} 2003000300003 \& \operatorname{lng}=\mathrm{en} \& \mathrm{nrm}=\mathrm{iso}>$. Acesso em: 6 jun. 2006. 